\title{
Examining Doctoral Student Development of a Researcher Identity

\author{
Using the Draw a Researcher Test
}

\author{
Micki M. Caskey, PhD \\ Professor and Doctoral Program Director \\ Portland State University \\ caskeym@pdx.edu \\ Dannelle D. Stevens, PhD \\ Professor Emerita \\ Portland State University \\ stevensd@pdx.edu \\ Marie Yeo \\ English Teacher \\ Yuga Elementary School \\ mariejolie4u@gmail.com
}

\begin{abstract}
With a core identity as working professionals, education doctoral students struggle with seeing themselves as researchers. Because research is essential in a doctoral program, the sooner doctoral students include researcher as an identity, the smoother and more successful their journey will be. To support doctoral student researcher identity development, we focused on scaffolding and embedding academic writing experiences in the first year seminar in a U.S. doctoral program. The purpose of this study was to describe and explain doctoral students' development of a researcher identity as measured by the Draw-a-Researcher Test (DART). In the fall and spring, we collected drawings (DART) and narrative reflections from nine students. We created a five-dimension DART scoring guide. In the fall, the drawings revealed students' uncertainty about the agency (ability to make changes) and the research process dimensions; in the spring, however, the drawings showed students' clearer understanding of these two dimensions. In the narrative reflections, students noted the influence of writing expectations and experiences on their role identity as researchers. Implications, as measured by the DART, are that an embedded writing support model seems to assure the development of doctoral students' core identity as researchers during the first year of the program.
\end{abstract}

Keywords: education doctorate (EdD), doctoral students, Draw-a-Researcher Test, researchers, identity, scholarly practitioners, visual data

\section{INTRODUCTION}

As the sugar maple trees shook off their golden leaves in the fall, our new cohort of education doctoral students stepped into their first research seminar. None took a typical path of moving seamlessly from their bachelors' and masters' degrees to a doctoral program. Instead all came from the world of working professionals. Among them were a high school science teacher, a middle school social studies teacher, a university student services coordinator, an adjunct faculty member in teacher education, a director of special education, a mentor in a police academy as well as three international students: a Korean elementary school teacher, a Korean college language teacher, and a college Chinese English language teacher. As seminar leaders over the first two years of the program, our job was to guide this diverse group of doctoral students along the path to have the tools, skills, and dispositions to design and conduct a research project. Those who study doctoral education have asserted that the doctorate is as much about developing an identity as a researcher as it is about being a knowledgeable consumer of research (Colbeck, 2008; Green, 2005). In fact, Colbeck (2008) acknowledged that developing an identity as a researcher is "an essential task for a doctoral student" (p. 9). According to Mantai (2015), "In becoming a researcher, [doctoral] candidates need to 'negotiate new identities and reconceptualize themselves both as people and professionals' (Hall \& Burns, 2009, p. 1 ) in addition to acquiring research skills" (p. 636). Thus, researcher identity is a central developmental challenge for students.

Yet, what does it mean to have an "identity"? Burke (2003a) suggested that having an identity is "to be who one is" (p. 1). He asserted that an individual has multiple identities across the life span that include social, role, and personal aspects (Burke, 2003b).

Those identities explain current behavior and predict future behavior. Researcher identity is certainly one of those multiple identities that has a powerful influence over one's approach and resilience toward
New articles in this journal are licensed under a Creative Commons Attribution 4.0 United States License.

This journal is published by the University Library System of the University of Pittsburgh as part of its D-Scribe Digital Publishing Program and is cosponsored by the University of Pittsburgh Press.

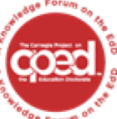

This journal is supported by the Carnegie Project on the Education Doctorate: A Knowledge Forum on the EdD (CPED) cpedinitiative.org
ISSN 2472-5889 (online) DOI 10.5195/ie.2020.92 
conducting research. Because identities develop over time, it seems fruitful to track researcher identity development- not just at a one point in time but over time-for doctoral students who seek to complete a heavily research-infused task: a dissertation.

\section{CONCEPTUAL FRAMEWORK}

To explore doctoral students' perceptions and the development as researchers, we used identity as a conceptual framework. In Erikson's (1968) classical theory of psychosocial development, people experience stages of development over their life span. One of these stages is identity vs. identity confusion. Movement across this stage, according to Erikson, is a "turning point"- "a crucial period of increased vulnerability and heightened potential" (p. 96). It is when people develop a sense of inner identity and an identity within the society because identity is a fluid construct over a lifetime. In addition, he recognized that identity is not a static construct: it changes over time as the individual has a variety of life experiences.

In more recent years, scholars elaborated the concept of identity. Based on a systematic review of literature, Gee (2000) summarized and classified multiple ways to view identity. Gee's seminal work legitimized a broader and more nuanced study of identity that added to Erickson's initial conceptualizations. Similarly, Burke (2003b) asserted that an individual has multiple identities across the life span that include social, role, and personal aspects. Adding to the identity discourse, Sfard and Prusak (2005) defined identity "as a set of reifying, significant, endorsable stories about a person" (p. 14), consisting of actual identity (e.g., "I am a student," "I am a good person") and designated identity (e.g., "I want to be a teacher," "I need to be a better person"). Offering a different perspective, Flum and Kaplan (2012) viewed "identity is an integrative concept and it is developed in the space between the individual and the social context" (p. 244). Scholars have tussled back and forth, not about the value of using identity as a construct to understand human behavior, but about how to define it. What we glean from this body of work is that identity is multifaceted, and includes social, personal, and role aspects.

Our education doctoral students are working professionals who have a variety of identities. They possess highly developed identities including personal identities (e.g., political party or religious affiliation), social identities (e.g., parents, daughters) and role identities (e.g., teachers, principals). We are interested specifically in role identity-how people occupy a role and incorporate that role into themselves including the "expectations associated with that role and its performance" (Stets \& Burke, 2000, p. 225). For this reason, and given our interest in fostering researcher identity, we focused on understanding the development of doctoral students' role identities as researchers.

\section{LITERATURE REVIEW}

Education doctoral students enter their programs with success in a profession, such as a teacher, P-12 school administrator, or higher education administrator. While these doctoral students possess skills and knowledge related to success in their professions, many have limited background in or experience with research (Brew, Boud, \& Namgung, 2011; Murakami-Ramalho, Militello, \& Piert, 2013; Zambo, Buss, \& Zambo, 2013). In some cases, these students have completed a teacher work sample or another competency-based assessment of their teaching or administrative performance but not a thesis or research project that is a typical requirement of traditional master's degree program. Gardner (2008) pointed out doctoral students might not be adequately prepared for the transition from student to researcher. Therefore, some education doctoral students may start their doctoral degree program with an understandably underdeveloped sense of researchers in general and educational researchers, specifically. In other cases, even for those who may have completed a traditional masters' degree or even undergraduate thesis with a research component, these experiences may have been several years ago and do not represent the level and depth of skill required for doctoral research.

Because many education doctoral students lack experience in conducting research or have conducted it a long time ago and under less demanding conditions, they may not feel competent in research and, therefore, have not developed an identity as a researcher. According to Taylor (2007), though experts in their profession, doctoral students often feel the tension of seeing themselves as novices in the research world. Murakami-Ramalho et al. (2013) found that the expectation of developing a researcher identity lead doctoral students to feel quite concerned about becoming a researcher. Others have also found that many students find significant challenges with the expectation that they conduct research (Colbeck, 2008; McAlpine, 2012; McAlpine \& Amundsen, 2009). Yet, in the Carnegie Project on the Education Doctorate (2019), an established consortium of education doctoral programs to which we belong, students are expected to become researchersscholarly practitioners who read, write, conduct and apply research to their professional practice. Nevertheless, their initial images of researchers might include superficial stereotypical perceptions about research and researchers.

Building on their identity of accomplished practitioners when entering a doctoral program, education doctoral students need to develop an identity as researchers. Where and how can they develop the identity as researchers? Can doctoral programs play an active role in promoting researcher identity development? According to Zambo et al. (2013), doctoral programs can support the doctoral students' development as researchers, that is, scholarly practitioners who conduct research. However, supporting doctoral students is not simple.

Jazvac-Martek (2009) argued that the process by which student identity as researchers develop is complex. They asserted, "The academic identity [including researcher identity] that develops through the doctoral journey represents a dynamic configuration of elements that are simultaneously internal, or psychological and developmental, and external, involving the social and disciplinary" ( $p$. 253). Like all identity development, when doctoral students begin to see themselves as researchers, it influences their current and future behavior as well as their interpretations of behavior (Jazvac-Martek, 2009). Doctoral students' identity as researchers helps them take a more active role in their academic journey (Sinclair, Barnacle, \& Cuthbert, 2014). Yet, Jazvac-Martek (2009) noted the relationship between doctoral students' program experiences and emerging identities as scholars and researchers has not been "a central focus in research on the doctorate" (p. 253). Therefore, we still have much to learn from programs that attend to doctoral student researcher identity development. Exploring the experiences and reflections of doctoral students may lead to a greater understanding of what programs can do to further doctoral students' researcher identity. Our assumption is that the sooner that doctoral students develop an 
identity as a researcher, the more successful they will be in their EdD programs and beyond.

\section{PURPOSE OF STUDY}

As noted previously, the purpose of this study was to describe and explain educational doctoral students' development of a researcher identity during the first year of their program as measured by the Draw-a-Researcher Test (DART). We considered the program assignments and experiences that may have influenced education doctoral student development as researchers. To guide our investigation, we used the following research questions:

1. What do doctoral students' images and reflections indicate about their identity development as researchers?

2. What experiences do doctoral students indicate contributed to the development of researcher identity?

\section{RESEARCH METHODS}

Researchers have studied the development of identity over time within specific disciplines and with a variety of methods. For instance, Tonso (2006) examined the development of an engineer identity using ethnographic methods that include participant observations, field notes, and individual interviews. With regard to doctoral education, several researchers investigated the development of identity among doctoral students using methods such as surveys, focus groups, logs, and interviews (Jazvac-Martek, 2009; Mantai, 2015; McAlpine \& Amundsen, 2009; McAlpine, Jazvac-Martek, \& Hopwood, 2009; Sinclair et al. 2014; Zambo et al., 2013). While all of these methods have provided valuable data, we wanted to explore the use of visual data to capture student development of a researcher identity. Visual data might have the advantage of tapping an inner, richer, and deeper understanding of what it means to be a researcher. Following the extensive work on the Draw-a-Scientist Test, Finson (2009) helped to explain the theory underlying the development of images in our heads. He clarified:

The theory providing the underpinnings of using drawings to derive data about individual's perceptions of scientists is relatively straightforward. We develop ideas about things, or form concepts about them, sometimes with very little factual information. As we gain more information, our conceptions become more sophisticated as we assimilate it [sic] into our mental schema. (p. 64)

We reasoned that our students did not have much factual information about the complexities of being a researcher. We sensed that the development of a researcher identity would involve a change in students' mental schema of researchers that could be exhibited in their drawings of researchers. Thus, we collected our doctoral students' hand-drawn images of researchers at the beginning and end of their first year in the program. At the end of the first year, we also collected their narrative reflections on these two images.

Given the importance of doctoral students' identity as researchers and the gap in research on how students actually develop that identity, we chose a well-established but not typical method of assessing student perceptions of themselves as researchers based on the work with the Draw-a-Scientist Test. We based the rationale for the data collection task, Draw-a-Researcher (DART), on the pioneering work of Chambers (1983) who examined school children's stereotypical views of scientists through drawings.
Chambers based his rationale on Goodenough's (1926) work with the Draw-a-Man Test that assessed the psychological state of the person making the drawing. Chambers (1983) and Finson (2009) extended the implications from the Draw-a-Man Test to focus mostly on the children's drawings of scientists. Following Goodenough, they argued that the drawings offer significant data about children's mental images and ideas without limiting their responses to verbal or written data. Finson (2009) further explained, "... If we approach those drawings with a purpose and protocol, then, we have visual data" (p. 59). He asserted that having a purpose and a protocol changes the focus from a mere drawing to visual data that can be analyzed to derive meaning.

Our work extends the work on using drawings as visual data. Much of the previous work examined children's conceptions of scientists (Finson, 2002; Finson, Pedersen, \& Thomas, 2006). Others used drawings to understand children's conceptions of engineers (Capobianco, Diefes-Dux, Mena, \& Weller, 2011; Capobianco \& Mena, 2013; Knight \& Cunningham, 2004) and perceptions of reading (Zambo, 2006). Researchers have used versions of the Draw-a-Scientist Test with adults to examine (a) preservice teachers' views of scientists (Miele, 2014; Milford \& Tippett, 2013), (b) teachers view of teachers teaching (Sinclair, Szabo, Redmond-Sanogo, \& Sennette, 2013), (c) mathematics teachers' views (Utley \& Showalter, 2007), and engineering students' views of engineers (Singer, Foutz, Navarro, \& Thompson, 2015). In addition, Miele (2014) collected pre- and post-drawings to note changes in images over time. Sinclair et al. (2013) used a modified Draw-a-Scientist Test asking preservice and inservice teachers to draw a teacher teaching. The teachers were asked to reflect on their images of teachers with a checklist as to whether it was teachercentered, student-centered, or in between. Next, they discussed what their drawings meant about their own views of teaching. Thus, the drawings can be used with adults as a self-reflective tool. Based on Finson's (2009) theory, people's mental schema change over time as they have more experiences; therefore, people's mental images and drawings should change with experience.

In the following sections, we provide a description of the context, participants, data collection process, the Draw-a-Research Test, and data analyses.

\section{Context}

The context for this study was a large comprehensive urban university (28,000 students) in the United States. The school of education faculty designed the educational doctoral program for working professionals to guide students in becoming scholarly practitioners. The faculty aligned the program with the working principles of Carnegie Project for the Education Doctorate (2019), a consortium of universities and colleges that gather together to discuss and refine programs that offer an education doctorate (EdD). Our four-year doctoral program admitted students in groups by specialization area (e.g., curriculum and instruction or educational leadership). Our group was limited to a broad range of educators with a curriculum and instruction rather than an educational administration background.

In our doctoral program, students attended courses and seminars on Friday evening and Saturdays in a hybrid format, half the classes online and the other half face-to-face. On Saturdays during the first year of the four-year program, the cohort completed three of the six core courses (i.e., learning theories, organizational 
leadership theories, policy and political theories). In the second year, the students completed three other courses (research paradigms, qualitative methods, quantitative methods). In addition, on Friday nights, students were divided into two learning communities and participated in seminars that met for four hours, four times a term (fall, winter, spring). For this exploratory study, we examined the seminar experiences of our learning community $(n=9)$ during the first year of the program. Intentionally creating a student learning community-a community of practice (Wenger, 1998) —was one of the program's signature pedagogies (Shulman, 2005). We were the advisors and instructors of the Friday night seminar learning community, and we focused this investigation on these doctoral students.
The design of the academic writing program within our seminar was based on recent literature about academic writing. As DicksonSwift, James, Kippen, Verrinder, \& Ward (2009) noted "A research culture is a writing culture. If we are to build a research culture then we have to see writing as central to that process" (p. 229). We selected modeling, coaching, and scaffolding as our seminar teaching methods to support student engagement and to encourage students to tap and adapt their experiences as working professionals to this new challenge. A key feature of the seminar was the opportunity for students to learn and practice the intentional use of academic writing strategies (see Table 1) to develop their writing and thinking abilities related to doing research, and therefore, adopting a new identity as researchers.

Table 1. Alignment of Student Writing Objectives and Research-based Strategies

\begin{tabular}{|c|c|}
\hline Student Writing Objective & Research Based Strategies for Each Objective \\
\hline $\begin{array}{l}\text { Understand and practice the underlying structures of } \\
\text { academic writing }\end{array}$ & $\begin{array}{l}\text { Rhetorical structures (Author, 2019; Graff \& Birkenstein, } \\
\text { 2010) }\end{array}$ \\
\hline $\begin{array}{l}\text { Build confidence in using your own experience and } \\
\text { voice }\end{array}$ & $\begin{array}{l}\text { Purpose statements (Goodson 2013) } \\
\text { Key sentences (Gray, 2010) }\end{array}$ \\
\hline $\begin{array}{l}\text { Set up your writing environment for focus, } \\
\text { accountability, and momentum }\end{array}$ & $\begin{array}{l}\text { Freewriting (Elbow, 1973) } \\
\text { Focused freewriting (Steven \& Cooper, 2009) } \\
\text { Keeping a journal (Steven \& Cooper, 2009) } \\
\text { Goal setting chart (Silvia, 2007) } \\
\text { Writing groups (Aitchison \& Guerin, 2014; Lee \& Boud, } \\
\text { 2003; Maher, Fallucca, \& Mulhern-Halasz, 2013) }\end{array}$ \\
\hline
\end{tabular}

We taught students to apply these research-based writing strategies to their course assignments to make the connection between doing research and writing about research. Examples of the research-related assignments from the seminar include:

- $\quad$ Drafting and submitting an Institutional Review Board application for a mini-research project prior to dissertation research;

- $\quad$ Presenting the results of the mini-research project in a poster session within the seminar;

- Writing the core paper qualifying exam.

\section{Participants}

The participants were nine doctoral students in the EdD. While this doctoral cohort had 12 members, during the analysis we excluded students who did not have a complete set of drawings and related narratives. Thus, the participants were seven women and two men. As noted in the introduction, their disciplinary interests and experiences as educators varied considerably including multicultural education, heritage language education, secondary education, and higher education. Of the nine participants, three were full time, international students whose primary language was not English; the other six held professional positions in $\mathrm{P}-12$ education or higher education. Our participants' experience with research during their master's degrees was disparate and ranged from completion of a teacher work sample to a thesis or an action research project.

\section{Data Collection and the Draw-a-Researcher Test}

We conducted the Draw-a-Researcher Test during a 10-month period in the first year of the doctoral program. Before collecting data, we secured Institutional Review Board (IRB) approval to describe and explain participants' experiences in the doctoral program as well as their perceptions of themselves as aspiring researchers. Because decades of research showed that that the Draw-a-Scientist Test hand-drawn images reflect a person's deeply held beliefs (Finson, 2002), we adapted the Draw-a-Scientist Test (Chambers, 1983) and created a Draw-a-Researcher Test. Our goal 
was to capture out student's deeply held beliefs about researchers through their hand-drawn images.

We gave each student a blank sheet of paper, provided colored pencils, and said, "Draw a researcher." We did not say, "Draw yourself as a researcher." We had the students complete these same steps, twice: once in September at the very beginning of the program, and again in their last class seminar in June at the end of their first year. In the June seminar, after doctoral students were asked to "Draw a researcher," we gave them their first drawing from September as well as another sheet of paper and asked them to write a narrative to address these questions: What do you see across the two drawings? What are the differences? Why do you think the drawings changed? Then, we collected both Draw-aResearcher drawings and their narrative reflections for analysis.

\section{Data Analysis}

After de-identifying all of the drawings and looking across both the fall and spring drawings, we first noticed a great variety of overall images from metaphors (e.g., farmer in a field, octopus, sea turtle, juggler) to cartoons (e.g., a person with three eyes and six legs) to realistic drawings (e.g., researcher in library). This variety of responses seemed to indicate that the doctoral students responded to the prompt to "draw a researcher" with what came to mind. Thus, we felt confident that their drawings were representative of their mental schema of a researcher at that time.

As for our more in-depth analysis, we had three data sets related to the drawings: (a) a DART drawing from the first meeting of the fall seminar, (b) a DART drawing from June at the end of their first year, and (c) a reflective narrative the doctoral students wrote in June when comparing their two drawings. After transcribing the narratives, we began to think about ways the drawings captured the idea of researcher identity. We reviewed Farland-Smith's (2012) Draw-a-Scientist Test Rubric and found it to be more general than others had used. Previous Draw-a-Scientist work focused on singular traits like wearing glasses, frizzy hair, lab coat, that is, artifacts that seemed to indicate the respondents' image of a scientist (Finson, 2002). Farland-Smith, however, assessed her drawings with specific dimensions like appearance (what a scientist looks like), location (where a scientist works) and activity (what a scientist does). In light of Farland-Smith's work with rubrics, we designed a tool-a scoring guide-for analyzing our doctoral students' DART drawings with specific dimensions like artifacts and setting as well as conceptual dimensions including metaphor, agency, and the research process that seemed to be part of a researcher identity.

Based on multiple reviews of the drawings and multiple readings of the narrative responses, we developed the scoring guide. We identified five dimensions: artifacts, setting, metaphor, agency, and research process. To clarify our use and the meaning of these dimensions, we defined them as follows:

- Artifacts are objects characteristically associated with research or the research process.

- Setting is a place or time where a researcher does his or her work.

- Metaphor is an image or word that represents an idea or process.
- "Agency refers to the thoughts and actions taken by people that express their individual power" (Cole, 2019, Para 1).

- Research process is a set of interrelated or interactive steps or stages that lead to an end goal

With these dimension descriptions in mind, we proceeded with our analysis of the researcher drawings looking for visual evidence of these dimensions within each specific drawing.

Subsequently, we analyzed the narrative data in which students' expressed their views of how their two drawings had changed over time. The analysis of these narratives extended our understanding of the students' drawings and their mental schemas of themselves as researchers.

\section{RESULTS}

In this section, we share the results of analyzing the participants' drawings with our newly developed DART scoring guide. Then, we present our analysis of the participants' narrative responses.

\section{Analysis of Draw-a-Researcher Drawings}

To analyze our students' Draw-a-Researcher drawings, we developed a scoring guide (rubric) with five dimensions (i.e., artifacts, setting, metaphor, agency, research process). Using the scoring guide, we-the three raters-coded each drawing independently, and then, compared our coding. During our discussion, we considered and resolved the minor differences in our codes and agreed upon a code for each drawing. In the next paragraphs, we describe our findings by dimension.

Artifacts. While we assumed that the drawings would include typical artifacts of doing research, we were surprised by the changes in the sheer number of artifacts from fall to spring. Across all drawings, our analysis showed a decrease in the number of specific artifacts (e.g., books, computers, desks, pens) from the fall (pre) to the spring (post). In the fall, nine students included 34 artifacts in their researcher drawings with a range of 1 artifact to 8 artifacts per drawing. However, in the spring, the nine students' drawings had only 18 total artifacts with four drawings having 0 artifacts and the others ranging from 1 to 6 artifacts. Comparing the change in the number of artifacts from fall to spring, the students drew fewer artifacts-explicit tools of a researcher after being in the program for one year.

Setting. We expected students to draw specific sites where an education researcher would conduct his or her research (e.g., library, school). The majority of students did not depict typical settings for conducting research. Looking across both sets of drawings (fall and spring), only three drawings showed typical settings for research such as a classroom, home office, library, and office. In eight of the 18 drawings the settings were unclear or vague. Seven drawings portrayed metaphors (e.g., farming) or depicted a metaphor in some way (e.g., farm).

Metaphor. Given the number of student drawings with metaphors, we added metaphor as a dimension in our scoring guide. We noted an increase in the use of metaphors from fall to spring. In the fall, two drawings used metaphors and two other drawings had metaphoric elements (can we give an example here?). In the spring, six drawings depicted metaphors and three drawings included 
metaphoric elements. The spring drawings included a diverse set of metaphors (e.g., farmer tending an orchard, farmer plowing a field, sea turtle floating in a sea).

Agency. By the aforementioned definition, "agency" speaks to an individual's thoughts and actions that represent their power. For this dimension, we found an increase in the number of actions (e.g., collaborating, observing, working) that represent the person's influence or thoughts from fall to spring. In the fall, seven of nine drawings did not illustrate a person engaged in a specific task. These fall drawings portrayed only one person engaged in an illdefined task, and one drawing included several people engaged in different tasks. In spring, eight of nine drawings showed people engaged in specific tasks (e.g., farmer tending an orchard, farmer plowing a field, woman reflecting on the research process as a series of bubbles in her head). The spring drawings revealed more action-more thoughts-and more agency than in the fall.

Research Process. As with some of the other dimensions, we noted a change in drawings about the research process from fall to spring. For example, one student's fall drawing showed a person with a big heart. Then, in the spring, the same student drew a farmer tending an orchard by watering the trees (i.e., conducting the literature review) and fertilizing the trees (i.e., reading and writing) to produce healthy fruit. Similarly, another student's fall drawing depicted the researcher as having six legs in motion, three eyes, and two hats. In the spring, the student's drawing showed a juggler in the process of juggling the specific tasks of a researcher (e.g., reading and writing, analyzing data). Another student had two scenes in the fall, a classroom and a person at a computer. His spring drawing was a concept map with an array of $x$ number of aspects of doing research radiating from the center. Not surprisingly given their completion of the first year in the doctoral program, the students' spring drawings seemed to reveal a greater understanding of the complex, iterative, and interactive nature of the research process.

\section{Summary of Draw-a-Researcher Drawings}

From the results of our analysis, we noted several differences between the fall and spring drawings. We found a significant decrease in specific artifacts in the spring. This finding may indicate that by the spring, the students had internalized the artifacts associated with conducting research (e.g., computer, books, pens) and had become aware of the greater complexity of the research process. With regard to setting, their drawings revealed both typical places (e.g., library) as well as metaphorical places (e.g., farm) for conducting research. Their drawings seemed to suggest that research entails more than the artifacts or the setting; the researcher needs to be actively involved (agency) in conducting research as well as understanding the many aspects of the research process. The use of metaphors to describe the work of a researcher seems to indicate that students could map the complexities of doing research to a task that might be more familiar to them.

What did we learn about the Draw-a-Researcher Test? Our scoring guide seemed to capture key dimensions of researcher identity. The artifacts and setting dimensions helped us to evaluate student conceptions of the context in which research is conducted. The three dimensions of metaphor, agency, and research process were critical in furthering our identification of the specific thoughts and actions that contribute to the development of a researcher identity. These three dimensions illustrate the dynamic nature of being a researcher.

\section{Participants' Narrative Responses about Their Drawings}

In their narratives about the two drawings, our participants' perceptions of researchers changed over time. They described their initial drawings (pre-) as general, and their second drawings (post-) as more concrete and explicit. From fall to spring, their ideas about researchers' work became more nuanced and revealed their awareness of the multifaceted nature of being a researcher. 

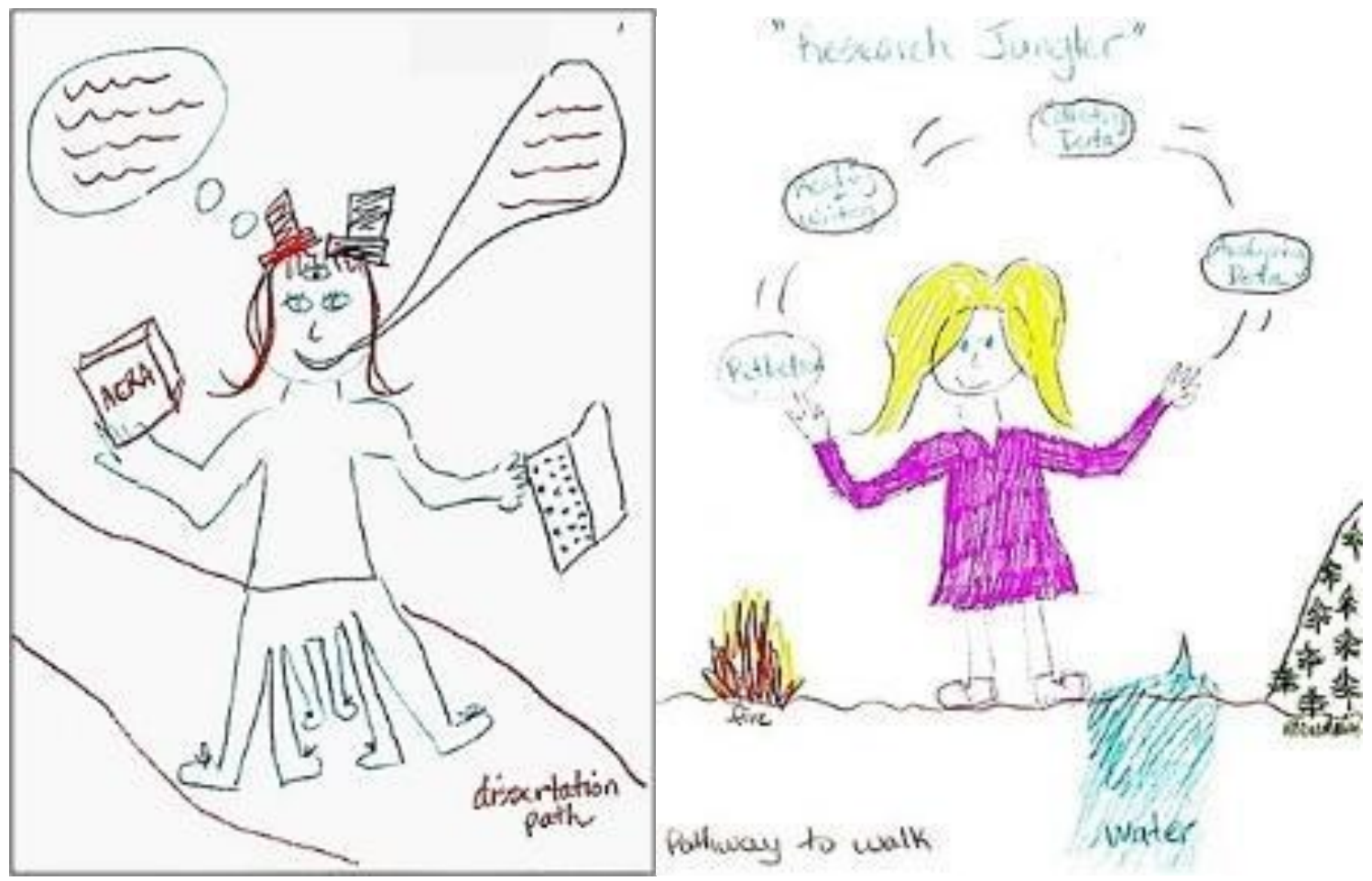

Figure 1. Diane's pre- and post- drawings for the Draw-a-Researcher Test

After examining her pre- and post- drawings (see Figure 1), Diana expressed:

In the first drawing, my multiple feet [were] going in different directions, which means an uncertainty about research.

However, one year later, I drew one path to go-even though there are obstacles along the road. Now, the direction is much clearer, and I am realistic about obstacles.

She added, "The path (in the doctoral program) is no longer just to dissertation as I realize that is only a part of it."
When comparing the pre- and post-drawings, we noted that participants also developed more specific and realistic images of researchers. For example, in the fall, Mary viewed a researcher as one who is highly intelligent and a know-all scholar. At the end of the first year, she described a researcher as an ordinary farmer in a field (see Figure 2). 


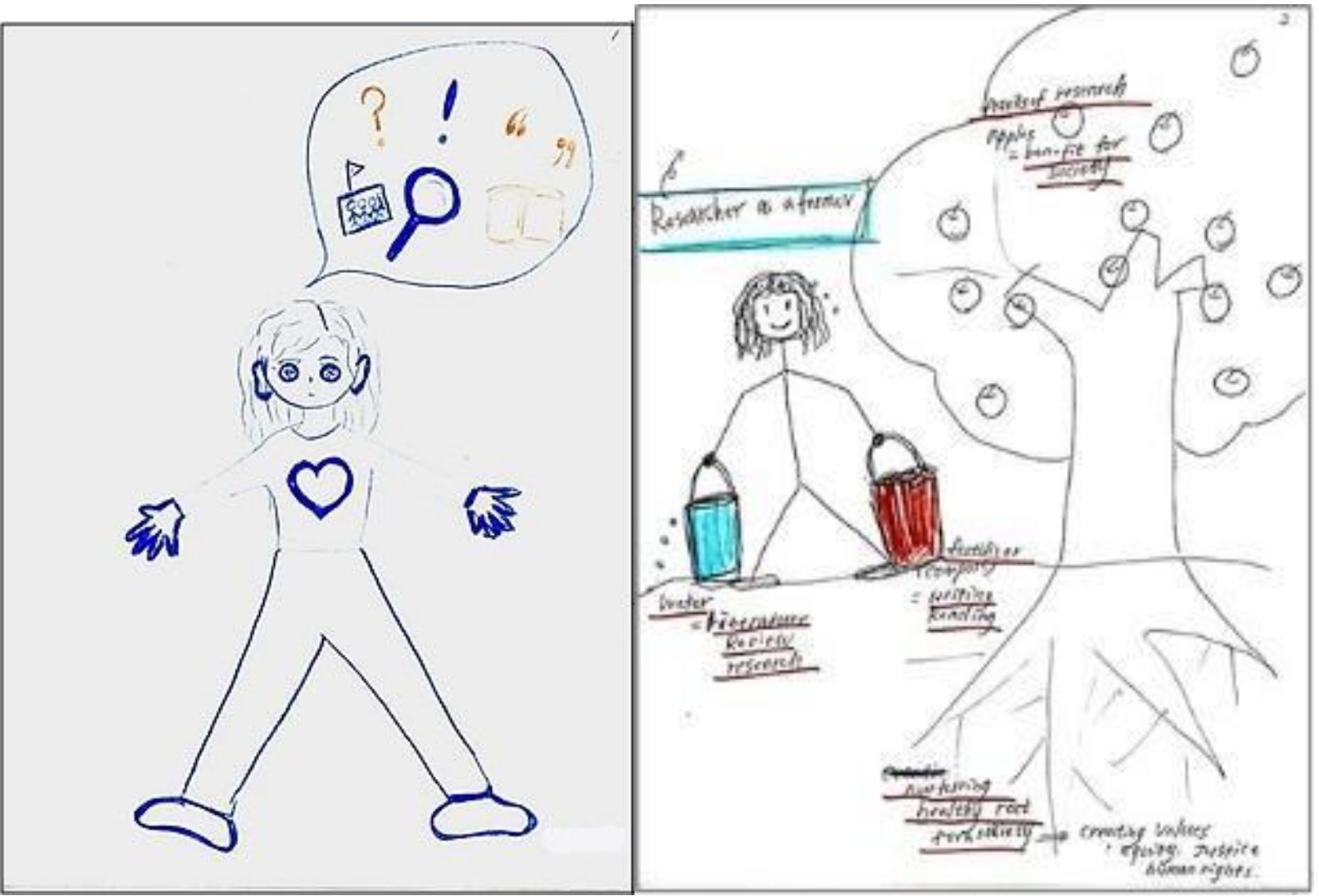

Figure 2. Mary's pre- and post-drawings for the Draw-a-Researcher Test

In her own words, Mary wrote:

In the beginning of my program, my drawing was a Know-all master teacher who knows everything, who gives wonderful instruction to students. Now, my drawing is a farmer in a field who is humble, honest, working constantly for a good harvest.

She also noted, "I drew researcher as someone who is a super intelligent woman. In my second drawing, the image changed into a farmer in an apple orchard." In her narrative reflection, Mary shared:

I have changed my perspectives on why I do research. I have begun to think about how my research can contribute [to] a society that I belong to. I transformed my goal as a researcher from 'academic study' to 'contribution to society.'

This is an example of how students developed a deeper knowledge about research and doctoral work; they have confidence and believe they are now more capable of conducting research.

Our students' narratives revealed their keen awareness of the changes they experienced in the first year of their EdD program. For instance, Lily offered insights into her own growth, sharing:

I notice that I become more practical now. From the first drawing I can see that I regard a researcher as someone capable of a lot of things he can teach; he's inquisitive all the time with a magnifier in hand, he's exploring. But there's a lot of uncertainly there. In the second drawing. I find that I'm more focused. A farmer is working in the field.

In this reflection, Lily referenced her use of a metaphor to characterize her certainty and clearer focus at the end of the first year.
With regard to the collaborative nature of research, Lynn reflected: "I see research and writing as part of that research as a collaborative process. This is completely different from fall term in my drawing where the researcher is in isolation." The questions are driving her research. Perhaps the artifacts, though important, are more integrated into the complex process of doing research now (e.g., APA, IRB). Being a researcher is more than just having the tools, you have to know how to use them in the process of doing the work. In a similar way, Mike disclosed his changed view of researchers, "[The] (b)efore [drawing] represented a very narcissistic 'me-focused' image... 'after'[drawing] hopefully represents a more community-centered collaborative paradigm." Lynn and Mark's reflections exemplified what we found when coding the drawings: an increased awareness of agency, as exemplified by collaboration.

In this study, the EdD program appeared to influence our EdD students' perceptions mental schemas of researchers. In their written reflections, they noted that courses and seminars helped to bring them clearer understandings of research and the researcher role. As Sara expressed:

At the beginning, it was vague and [l] did not know how to start... But taking core classes, things are clearer than before. Now I have a clear understanding of a researcher and his duties. I can see positive changes.

In this case, Sara stated explicitly what we saw evidenced in the drawings-a greater grasp of the research process. Our students also referenced experiences (e.g., preparing an IRB proposal, conducing a mini-research project, writing a comprehensive paper) 
that were supportive and prompted more realistic understandings of being a researcher. For example, Mark mused:

I think there's more emphasis now on production than there was in the fall. I have more knowledge (the metaphor of more books in the background), so now it's time to do something with it rather than just acquire. It makes sense that the emphasis has changed as that's where I am at. I am certainly still acquiring information, but I am to a point where I have to put the core paper [comprehensive paper] out there now.

Production is what's important.

Taken collectively, these narrative reflections helped us to hear our students' voices and gain an appreciation of their journey to develop a researcher identity. In addition, it seems that our doctoral students understood more about the complexity of doing research as well as the steps needed to navigate that complexity. Some students acknowledged that doing research has a broader potential benefit to the society as a whole.

\section{LIMITATIONS}

We acknowledge a number of research limitations including the small sample size and possible researcher bias. Regarding the sample size, only nine doctoral students completed two DART drawings and a narrative reflection comparing their drawing (i.e., a complete data set). Of the three students who did not complete two drawings, two students joined the seminar in winter term, and one student missed the last seminar. We acknowledge that the missing data may have influenced our analysis and findings; however, we suggest that complete data sets were imperative for studying developmental change. As noted, our aim was to describe and explain our students' development of a researcher identity during their doctoral program using a new measure, the DART. While the data set is small, the use of this kind of visual data in understanding identity development is unique and may offer other researchers a new lens by which to explore doctoral student identity development.

Another limitation of this study is the potential to introduce researcher bias in the data collection and analysis process. Specifically, a power differential existed between us (i.e., researchers) and the participants. We attempted to mitigate this bias by using the least obtrusive data collection process (Creswell, 2014) - in this case, the DART and narrative reflections. These two tasks were in keeping with other seminar activities our doctoral students completed during the first year of their program. As researchers, we may have also introduced bias when analyzing the data. We may have seen what we wanted to see (Merriam \& Tisdell, 2016). To address this limitation, we analyzed the DART drawings and reflective narrative independently. Then, we compared, discussed, and resolved any differences in our individual analyses. While researcher bias may still have influenced our analysis and findings, we contend that our approach may have helped us to mitigate researcher bias.

\section{CONCLUSION}

We acknowledge a number of research limitations including the small sample size and possible researcher bias. Regarding the sample size, only nine doctoral students completed two DART drawings and a narrative reflections comparing their drawing (i.e., a complete data set). Of the three students who did not complete two drawings, two students joined the seminar in winter term, and one student missed the last seminar. We acknowledge that the missing data may have influenced our analysis and findings; however, we suggest that complete data sets were imperative for studying developmental change. As noted, our aim was to describe and explain our students' development of a researcher identity during their doctoral program using a new measure, the DART. While the data set is small, the use of this kind of visual data in understanding identity development is unique and may offer other researchers a new lens by which to explore doctoral student identity development.

\section{Summary of Findings}

We contend that our investigation adds to the knowledge base about doctoral students' development of a researcher identity in two ways. First, in the narratives about their drawings, students mentioned the fact that our writing model (an IRB proposal, a miniresearch project, and a poster session about their project) seemed to lead to greater agency and a more complex understanding of the research process and navigation of that complexity. Furthermore, our intentional use of strategies in the seminars improved students' academic writing, which in turn, seemed to contribute to their sense of agency in approaching the many writing tasks associated with research.

Second, the DART offers a unique and parsimonious way of investigating doctoral student identity development as researchers. Building on prior research (e.g., Finson, 2002, Farland-Smith, 2012) and our multiple reviews of data (i.e., researcher drawings and reflective narratives), we developed and defined the five dimensions of the DART scoring guide: artifacts, setting, metaphor, agency, and the research process. The artifacts and setting dimensions helped us to examine student conceptions of the context in which research is conducted. In addition, using metaphor, agency, and the research process dimensions, we could evaluate student drawings regarding their mental schemas about research: what is it, how do you do it, and what are the results of doing research. Our findings suggest that the DART and DART scoring guide could be worthwhile tools for measuring doctoral students' development of a researcher identity.

\section{Significance}

Our results may shed new light on the use of hand-drawn images for collecting data about people's perceptions-in this case doctoral students' perceptions-and how these are changed through experience. For decades, researchers have collected drawings from children and adults to gain insight into psychological states (Goodenough, 1926), stereotypes (Chambers, 1983; Miele, 2014; Milford \& Tippett, 2013), and mental images or ideas (Capobianco et al., 2011; Capobianco \& Mena, 2013; Finson, 2009; Knight \& Cunningham, 2004). We argue that our study adds to the growing body of research indicating that people's mental images or schemas change over time as they have more experiences. Our methodology was a tool for data collection that seems to be a robust and trustworthy way of examining identity development.

\section{Implications}

Findings from our investigation also complement those of earlier studies regarding doctoral student identity development (Colbeck, 2008; McAlpine, 2012; McAlpine \& Amundsen, 2009; Sinclair et al., 2013; Zambo et al., 2013). Our study has implications for 
understanding the various dimensions of doctoral students' identity development. In particular, we are curious about the dimension of agency and how it affects doctoral students' identity as researchers. We contend that our work contributes to existing knowledge of doctoral student agency (McAlpine \& Amundsen, 2009). Specifically, our results showed a connection between the doctoral pedagogies (i.e., research-based strategies) and doctoral students' agency. As instructors and advisors (i.e., supervisors), we encouraged, modeled, and provided opportunities for student agency. Our results align with McAlpine and Amundsen's (2009) findings about supervisors' modeling and affirming student agency. We remain interested in the dimension of agency as it holds implications for our pedagogical practice.

\section{Recommendations for Future Research}

The findings also pointed to potential connections among our use of research-informed writing strategies, research-focused assignments, and the development of researcher identity. This study, therefore, raised important future research questions including (a) which research-based strategies fostered the connection between academic writing and research? and (b) what other doctoral program features (e.g., cohorts) might influence how doctoral students develop a researcher identity?

A natural progression of this study would be further research using the DART and DART scoring guide with doctoral students. Suggestions for further research include replicating this study (a) with additional cohorts of students in the same EdD program, and (b) with EdD students at CPED-influenced EdD programs. Another possibility would be using the DART and DART scoring guide with doctoral students in $\mathrm{PhD}$ programs. Beyond replication, another suggestion would be to extend the time (e.g., two years) between the first and the second administration of DART. Future research might delve more deeply into each of the DART scoring guide dimensions (i.e., artifacts, setting, metaphor, agency, research process) related to the development a researcher identity.

\section{Recommendations for Practice}

Based on the findings of our study, we offer the following recommendations for future practice. First and foremost, doctoral program instructors and advisors need to consider the intentional use of research-based strategies (see Table 1) to support doctoral students' academic writing. We assert that writing is thinking. Through writing, students clarify their thinking. We contend that linking a set of writing strategies to key research-focused assignments may contribute to doctoral students' development of researcher identity. Second, doctoral programs need to continue to explore the role of a community of practice in doctoral student identity development. Our students worked in a cohort as well as small writing groups (3-4 people) that supported each person's thinking and writing. They participated in variety of seminar activities under the guidance of two seminar leaders over the year. Finally, we strongly suggest that instructors dissect key elements of the research process (e.g., doing a mini-research project, submitting an Institutional Review Board application) to give students the opportunity to practice and obtain feedback on their work before they tackle their dissertation proposal.

In conclusion, we know that our diverse group of working professionals adopted identities as researchers early in their doctoral program. Seeing themselves as researchers was one key step toward completion of the doctoral degree. In fact, all of the students in this study except one completed the doctoral program in four years. Of course, the students had other experiences with different instructors and advisors in the subsequent years; yet, we believe building a researcher identity early in the program is the solid foundation that doctoral students need.

\section{REFERENCES}

Aitchison, C., \& Guerin, C. (Eds.) (2014). Writing groups for doctoral education and beyond: Innovations in practice and theory. New York, NY: Routledge.

Brew, A., Boud, D., \& Namgung, S. (2011). Influences on the formation of academics: The role of the doctorate and structured development opportunities. Studies in Continuing Education, 33(1): 51-66.

Burke, P. J. (2003a). Introduction. In P. J. Burke, T. J. Owens, R. T. Serpe, \& P. A. Thoits (Eds.), Advances in identity theory and research (pp. 1-7). New York, NY: Kluwer Academic/Plenum.

Burke, P. J. (2003b). Relationships among multiple identities. In P. J. Burke, T. J. Owens, R. T. Serpe, \& P. A. Thoits (Eds.), Advances in identity theory and research (pp. 195-214). New York, NY: Kluwer Academic/Plenum.

Capobianco, B. M., Diefes-Dux, H. A., Mena, I., \& Weller, J. (2011). What is an engineer? Implications of elementary school student conceptions for engineering education. Journal of Engineering Education, 100, 304-328.

Capobianco, B. M., \& Mena, I. B. (2013). Longitudinal profiles of children's conceptions of an engineer. International Journal of Engineering Education, 29, 415-425.

Carnegie Project on the Education Doctorate. (2019). Guiding principles for program design. Retrieved from https://www.cpedinitiative.org/theframework

Chambers, D. (1983). Stereotype images of the scientist: The draw-a-scientist test. Science Education, 67, 255-65. doi: 10.1002/sce.3730670213

Colbeck, C. L. (2008). Professional identity development theory and doctoral education. New Directions for Teaching \& Learning, 2008(113), 9-16.

Cole, N. L. (2019, January 22). How sociologists define human agency. Retrieved from thoughtco.com/agency-definition-3026036

Creswell, J. W. (2014). Research design: Qualitative, quantitative, and mixed methods approaches $\left(4^{\text {th }}\right.$ ed.). Los Angeles, CA: SAGE.

Dickson-Swift, V., James, E. L., Kippen, S., Talbot, L., Verrinder, G., \& Ward, B. (2009). A non-residential alternative to off campus writers' retreats for academics. Journal of Further and Higher Education, 33(3), 229-239. doi.org/10.1080/03098770903026156

Elbow, P. (1973). Writing without teachers. New York, NY: Oxford University Press.

Erikson, E. H. (1968). Identity: Youth and crisis. New York, NY: Norton.

Farland-Smith, D. (2012). Development and field test of the modified raw-aScientist Test and the Draw-a-Scientist Rubric. School Science and Mathematics, 112(2), 109-116.

Finson, K. D. (2002). Drawing a scientist: What we do and do not know after fifty years of drawings. School Science \& Mathematics, 102, 335-45.

Finson, K. D. (2009). What drawings reveal about perceptions of scientists: Visual data operationally defined. In J. E. Pedersen \& K. D. Finson (Eds.), Visual data: Understanding and applying visual data to research in education (pp. 59-77). Rotterdam, The Netherlands: Sense.

Finson, K. D., Pedersen, J., \& Thomas, J. (2006). Comparing science teaching styles to students' perceptions of scientists. School Science and Mathematics, 106(1), 8-15.

Flum, H., \& Kaplan, A. (2012). Identity formation in educational settings: A contextualized view of theory and research in practice. Contemporary Educational Psychology, 37(3), 240-245. doi.org/10.1016/j.cedpsych.2012.01.003

Gardner, S. K. (2008). 'What's too much and what's too little?': The process of becoming an independent researcher in doctoral education. The Journal of Higher Education, 79, 326-50.

Gee, J. P. (2000). Identity as an analytic lens for research in education. Review of Research in Education, 25, 99-125. doi.org/10.2307/1167322

Goodenough, F. L. (1926). Measurement of intelligence by drawings. New York, NY: Harcourt Brace. 
Goodson, P. (2013). Becoming an academic writer: 50 exercises for paced, productive, and powerful writing. Thousand Oaks, CA: SAGE.

Graff, G., \& Birkenstein, C. (2010). They say/l say: The moves that matter in academic writing $\left(2^{\text {nd }}\right.$ ed. $)$. New York, NY: W. W. Norton.

Gray, T. (2010). Publish and flourish: Be a prolific scholar. Ashland, $\mathrm{OH}$ : Bookmasters.

Green, B. (2005). Unfinished business: Subjectivity and supervision. Higher Education Research \& Development, 24(2), 151-163. doi.org/10.1080/07294360500062953

Hall, L. A., \& Burns, L. D. (2009). Identity development and mentoring in doctoral education. Harvard Educational Review, 79(1), 49-70.

Jazvac-Martek, M. (2009). Oscillating role identities: The academic experiences of education doctoral students. Innovations in Education and Teaching International, 46(3), 253-264.

Knight, M., \& Cunningham, C. (2004). Draw an Engineer Test (DAET): Development of a tool to investigate students' ideas about engineers and engineering. Proceedings of the 2004 American Society for Engineering Education Annual Conference \& Exposition, Salt Lake City, UT.

Lee, A., \& Boud, D. (2003). Writing groups, change and academic identity: Research development as local practice. Studies in Higher Education, 28(2), 187-200. doi.org/10.1080/0307507032000058109

Maher, M., Fallucca, A., \& Mulhern Halasz, H. (2013). Write on! through to the Ph.D: Using writing groups to facilitate doctoral degree progress. Studies in Continuing Education, 35(2), 193-208. doi.org/10.1080/0158037X.2012.736381

Mantai, L. (2015). Feeling like a researcher: Experiences of early doctoral students in Australia. Studies in Higher Education, 42(4), 636-650. doi.org/10.1080/03075079.2015.1067603

McAlpine, L. (2012). Shining a light on doctoral reading: Implications for doctoral identities and pedagogies. Innovations in Education and Teaching International, 49(4), 351-361. doi.org/10.1080/14703297.2012.728875

McAlpine, L., \& Amundsen, C. (2009). Identity and agency: Pleasures and collegiality among the challenges of the doctoral journey. Studies in Continuing Education, 31(2), 109-125. https://doi.org/10.1080/01580370902927378

McAlpine, L., Jazvac-Martek, M., \& Hopwood. N. (2009). Doctoral student experience in education: Activities and difficulties influencing identity development. International Journal for Researcher Development, 1(1), 97-109.

Merriam, S. B., \& Tisdell, E. J. (2016). Qualitative research: A guide to design and implementation. San Francisco, CA: Jossey-Bass.

Miele, E. (2014). Using the Draw-a-Scientist Test for inquiry and evaluation. Journal of College Science Teaching, 43(4), 36-40.

Milford, T. M., \& Tippett, C. D. (2013). Preservice teachers' images of scientists: Do prior science experiences make a difference? Journal of Science Teacher Education, 24, 745-762. doi.org/10.1007/s10972-0129304-1

Murakami-Ramalho, E., Militello, M., \& Piert, J. (2013). A view from within: How doctoral students in educational administration develop research knowledge and identity. Studies in Higher Education 38(2), 256-271. doi:10.1080/03075079.2011.578738

Sfard, A., \& Prusak, A. (2005). Telling identities: In search of an analytic too for investigating learning as a culturally shaped activity. Educational Researcher, 34(4), 14-22.

Silvia, P. J. (2007). How to write a lot: A practical guide to productive academic writing. Washington, DC: American Psychological Association.

Sinclair, J., Barnacle, \& Cuthbert, D. (2014). How the doctorate contributes to the formation of active researchers: What the research tells us. Studies in Higher Education, 39(10), 1972-1286. doi:10.1080/03075079.2013.806460

Sinclair, B. B., Szabo, S., Redmond-Sanogo, A., \& Sennette, J. D. (2013). Investigating perceptions of teachers and teaching using the draw-ateacher checklist. Issues in Teacher Education, 22(1), 105-123.

Singer, K. P., Foutz, T., Navarro, M., \& Thompson, S. (2015). Investigating the extent that an integrative learning module broadens the perception of first-year students about the engineering profession. American Journal of Engineering Education, 6(2), 99-111).

Stets, J. E., \& Burke, P. J. (2000). Identity theory and social identity theory. Social Psychology Quarterly, 63(3), 224-237. doi.org/10.2307/2695870
Stevens, D. D., \& Cooper, J. E. (2009). Journal keeping: How to use reflective writing for learning, teaching, professional insight, and positive change. Sterling, VA: Stylus.

Taylor, A. (2007). Learning to become researching professionals: The case of the doctorate of education. International Journal of Teaching \& Learning in Higher Education, 19, 154-166.

Tonso, K. (2006). Student engineers and engineer identity: Campus engineer identities as figured world. Cultural Studies of Science Education, 1, 272-307.

Utley, J., \& Showalter, B. (2007). Preservice elementary teachers' visual Images of themselves as mathematics teachers. Focus on Learning Problems in Mathematics, 29(3), 1-15.

Wenger, E. (1998). Communities of practice: Learning, meaning, and identity. New York, NY: Cambridge University Press.

Zambo, D. (2006). Using thought-bubble pictures to assess students' feelings about reading. Reading Teacher, 59(8), 798-803. doi.org/10.1598/RT.59.8.7

Zambo, D., Buss, R. R., \& Zambo, R. (2013). Uncovering the identities of students and graduates in a CPED-influenced EdD Program. Studies in Higher Education, 40(2), 1-20. doi:10.1080/03075079.2013.823932 